\title{
Pharmacodynamic and Therapeutic Actions of Levothyroxine
}

\author{
James V. Hennessey
}

The regulation of thyroid hormones within the hypothalamic-pituitary-thyroid axis is complex, consisting of multiple feedback and feed-forward loops. In addition, this system contributes to and likely reflects the regulation of sensitivity to thyroid hormones at the level of other target tissues. The effects of levothyroxine (LT4) replacement therapy for people with hypothyroidism must be considered within this context, as many patients will have residual thyroid activity. LT4 replacement reverses many metabolic disturbances associated with hypothyroidism including resetting of reduced energy expenditure and metabolic rate, correction of dyslipidaemia, improvement in insulin sensitivity and glycaemic control, and reversal of a pro-inflammatory and procoagulant state, and the eventual correction of mood disturbances (although on the surface these appear more refractory to LT4 treatment than other consequences of hypothyroidism). Monotherapy with LT4 remains the mainstay of treatment for hypothyroidism, due to a lack of clinical evidence for superior treatment outcomes with combinations of LT4 and triiodothyronine.

\section{Introduction}

The opening chapters of this book outlined the historical development of levothyroxine (LT4) as a treatment for hypothyroidism and described the pharmacokinetic properties of exogenously applied levothyroxine. The purpose of this chapter is to summarise the therapeutic actions of LT4 in key organs of the body. Exogenous

\footnotetext{
J. V. Hennessey $(\bowtie)$

Harvard Medical School, Division of Endocrinology, Beth Israel Deaconess Medical Center,

Boston, MA, USA

e-mail: jhenness@bidmc.harvard.edu
} 


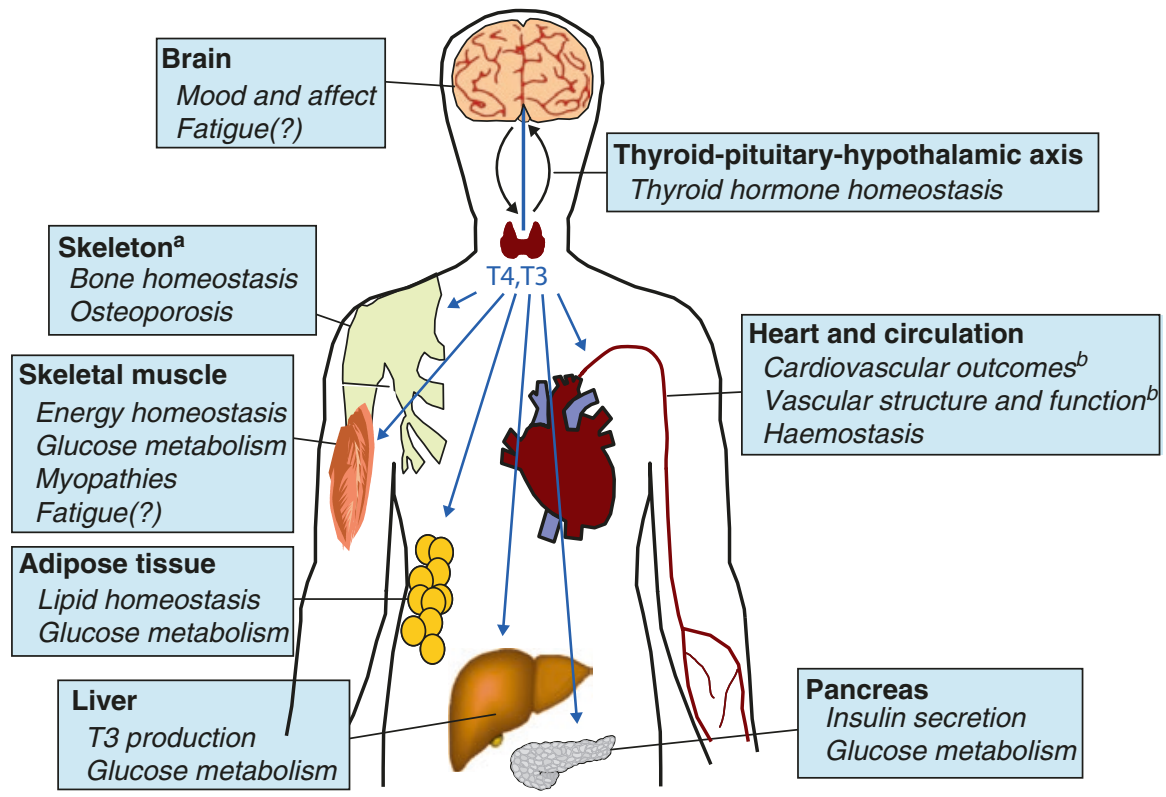

Fig. 1 Overview of key sites of thyroid hormone action. ${ }^{a, b}$ Not described in this chapter: see chapters, "Levothyroxine and the Heart ${ }^{\mathrm{a}}$ " and "Levothyroxine and Bone ${ }^{\mathrm{b}}$ "

LT4 is indistinguishable from endogenous T4, and so I have sought to summarise the biological actions of T4 per se, in terms of the regulation of secretion and action of thyroid hormones and the therapeutic effects of LT4 supplementation in people with hypothyroidism in key areas of the body (Fig. 1). This chapter will not include detailed descriptions of the effects of LT4 on the heart or the skeleton: these aspects are covered in chapters, "Levothyroxine and the Heart" and "Levothyroxine and Bone" of this book, respectively. Finally, I have considered the evolution and current status of guidelines for the management of hypothyroidism, and the current evidence base for the therapeutic use of LT4 monotherapy, the current mainstay of treatment for hypothyroidism.

\section{Thyroid Hormone Homeostasis}

A simplistic view of the hypothalomo-pituitary-thyroid (HPT) axis entails secretion of thyrotropin-releasing hormone (TRH) from the hypothalamus acting on the pituitary to enhance secretion of thyrotropin (thyroid-stimulating hormone, TSH) [1-3]. Increased circulating concentrations of TSH then stimulate release of thyroid hormones from the thyroid gland, with a negative feedback loop causing secretion of TSH to fall as the concentration of thyroid hormones in the blood and tissues increases. In practice, the operation of the HPT axis is extraordinarily complex. Key components of the HPT, illustrating some of these complexities, are summarised below [3]. 


\subsection{Conversion of T4 to T3}

T4 is the primary secretory product of the thyroid and accounts for about $60-80 \%$ of circulating thyroid hormones. Triiodothyronine (T3) accounts for most of the remainder (other molecular species such as diiothyronine, or reverse T3 may have biological activity [4], but are beyond the scope of this review). Eighty percent of the T3 found in the circulation is derived through peripheral activation of $\mathrm{T} 4$ while the remaining $20 \%$ of circulating T3 is produced in the thyroid. T4 (or exogenous LT4) is converted to T3 locally in target tissues, via the actions of three deiodinase enzymes, particularly Deiodinase 2 (see chapter, "Administration and Pharmacokinetics of Levothyroxine" for a fuller account of the functions of different deiodinases) [5].

\subsection{Regulation of Deiodinases and Individual "Set Points" for Thyroid Function}

The activity of intrathyroidal deiodinase is regulated by TSH in a feed-forward manner, providing a means of adjustment of local T3 levels as needed [3]. In addition, ubiquitination of Deiodinase 2 in some tissues reduces its activity; this occurs to a lesser extent in the hypothalamus than in some other tissues, which may increase sensitivity to feedback inhibition of TRH release by (L)T4 [6].

The relationship between TSH levels, free T3 and free T4 (FT3 and FT4) is not the same in a euthyroid healthy individual and a patient with thyroid disease treated with LT4 [7, 8]. In general, T4 levels (especially when measured in the post-absorptive state) tend to be higher once TSH is controlled to its reference range, compared with euthyroid individuals [9-11]. However, studies in hypothyroid patients rendered surgically athyroid who were titrated to a normal TSH with LT4 have also reported normalised T3 levels; in fact, $49 \%$ of those titrated to a normal TSH had higher T3 levels on LT4 than in their native preoperative state in one study [12]. A retrospective study of hypothyroid subjects on LT4 monotherapy reported lower FT3 levels than in healthy individuals [13]. Finally, in one retrospective study, serum T3 levels in subjects with an elevated or normal-range TSH were lower than the same individuals' preoperative values but surprisingly all were still within the normal reference range. In those with modest TSH suppression, T3 levels were no different from their native state while several of those with more complete suppression of TSH demonstrated frankly elevated T3 values [8]. Accordingly, each patient with thyroid dysfunction has an individual "set point" for optimum functioning of the HPT axis, whether levels of TSH, FT3, and FT4 are precisely within their formally defined reference ranges or not [14].

\subsection{Thyroid Hormone Receptors (THRs)}

THRs are nuclear receptors that bind T3 after uptake into cells via active transporters. The most important THRs for mediating the actions of thyroid hormones are $[13,15,16]$ : 
- THR $\alpha 1$ : expressed most strongly in bone, the gut, the central nervous system, and cardiac and skeletal muscle

- THR $\beta 1$ : expressed most strongly in the liver, kidney, and the inner ear

- THR $\beta 2$ : expressed most strongly in the hypothalamus, pituitary, cochlea, and retina

THR $\beta 2$ appears to be about ten-fold more sensitive than THR $\beta 1$ [13]. Loss-offunction mutations in THRs have been shown to produce elevated circulating T4 and T3 levels simultaneously with signs of a functional peripheral hypothyroidism [17].

\subsection{Regulation of TSH Release}

Production of TRH by the hypothalamus is an absolute requirement for the production of TSH, and thus thyroidal T4 [18]. TRH modulates the bioactivity of TSH, with more bioactive forms produced in the setting of thyroid deficiency [19]. TSH itself exerts an autocrine function in the pituitary and a paracrine function in the hypothalamus to inhibit further TSH release [20].

Importantly, TSH release is highly sensitive to the prevailing level of T4 in the circulation, such that reducing FT4 by half would typically increase the TSH level by up to 100-fold; conversely, a five-fold increase in the TSH level might be seen when FT4 is reduced by only about 10\% [21]. The relationship of TSH levels to FT4 levels has been described as inverse log-linear although more complex non-linear associations have been described [22-25]. This relationship is the main reason why the TSH level is used to guide treatment of hypothyroidism with LT4, as the large changes in TSH are far easier to measure than small changes in T4 or FT4 (within the traditional 95\% normal range) in the routine setting $[21,26]$. Multiple factors, such as age, gender, smoking, the presence of antithyroid antibodies, and the difference between prevailing thyroid hormone levels and an individual's "set point" for HPT axis function (see above), influence the shape of the relationship between TSH and FT4 levels [22, 23, 25].

\section{Clinical Pharmacodynamics of (Levo)Thyroxine}

\subsection{Which Thyroid Hormones Are Important?}

LT4 acts essentially as a prodrug of T3 in target tissues, via the actions of the deiodinase enzymes, described above [5]. Accordingly, this section will include information on the effects of hypothyroidism on key organs of the body, as well as the restorative 
Table 1 Overview of the pharmacodynamics of LT4 in key physiological or organ systems in patients with hypothyroidism

\begin{tabular}{|c|c|c|}
\hline $\begin{array}{l}\text { Physiological } \\
\text { process }\end{array}$ & $\begin{array}{l}\text { Influence of } \\
\text { hypothyroidism }\end{array}$ & $\begin{array}{l}\text { Principal effects of LT4 replacement in a } \\
\text { patient with hypothyroidism }\end{array}$ \\
\hline Energy expenditure & Reduced & $\begin{array}{l}\text { Reverses reductions in resting energy } \\
\text { expenditure and metabolic rate }\end{array}$ \\
\hline Lipid profiles & $\begin{array}{l}\text { Promotes dyslipidaemia } \\
\text { mainly via } \downarrow \text { hepatic LDL } \\
\text { receptors }\end{array}$ & $\begin{array}{l}\text { Reduces total and LDL-cholesterol, and other } \\
\text { markers of dyslipidaemia } \\
\text { Reduces intrahepatic lipid content (where } \\
\text { elevated) }\end{array}$ \\
\hline $\begin{array}{l}\text { Blood glucose } \\
\text { control }\end{array}$ & $\begin{array}{l}\text { Overt hypothyroidism } \\
\text { mitigates IGT } \\
\text { Subclinical hypothyroidism } \\
\text { increases insulin resistance } \\
\text { and risk of diabetes }\end{array}$ & $\begin{array}{l}\text { Corrects changes of IGT in thyrotoxicosis } \\
\text { Improves insulin sensitivity } \\
\text { Improves glucose tolerance }\end{array}$ \\
\hline Inflammation & $\begin{array}{l}\text { Increased systemic } \\
\text { inflammation }\end{array}$ & Reduced markers of systemic inflammation \\
\hline Coagulation $^{\mathrm{a}}$ & $\begin{array}{l}\text { Overt hypocoagulant state } \\
\text { often induces coagulopathy } \\
\text { similar to aVWS } \\
\text { Subclinical hypothyroidism } \\
\text { induces a procoagulant } \\
\text { state }\end{array}$ & $\begin{array}{l}\text { LT4 corrects deficiencies } \\
\text { Improved markers of fibrinolysis and } \\
\text { coagulation }\end{array}$ \\
\hline Brain & Altered mood/affect & $\begin{array}{l}\text { Evidence for improved mood/affect (e.g. } \\
\text { reduced depression questionnaire scores) }\end{array}$ \\
\hline Adipose tissue & $\begin{array}{l}\text { Modest } \uparrow \text { weight } \\
\downarrow \text { Brown fat activation }\end{array}$ & $\begin{array}{l}\text { Reverses weight gain in hypothyroidism (but } \\
\text { little effect on body composition) }\end{array}$ \\
\hline Heart $^{\mathrm{a}}$ & $\begin{array}{l}\text { Exacerbates existing } \\
\text { cardiac issues } \\
\text { Reduced cardiac } \\
\text { contractility } \\
\text { Increased blood pressure }\end{array}$ & $\begin{array}{l}\text { Reverses abnormalities in cardiac structure } \\
\text { and function }\end{array}$ \\
\hline Bone $^{\mathrm{a}}$ & $\begin{array}{l}\text { Thyroid hormones reduce } \\
\text { bone density }\end{array}$ & $\begin{array}{l}\text { Over treatment and hyperthyroidism may } \\
\text { cause excessive bone loss } \\
\text { Thyroid function must be assessed especially } \\
\text { carefully in people at risk of fractures }\end{array}$ \\
\hline Kidney & $\begin{array}{l}\text { Hypothyroidism can } \\
\text { reduce renal function }\end{array}$ & $\begin{array}{l}\text { Reverses hypothyroidism-induced reduction } \\
\text { in GFR } \\
\text { Some evidence of benefit (reduced decline in } \\
\text { GFR, reduced uric acid and albumin } \\
\text { excretion) }\end{array}$ \\
\hline QoL & $\begin{array}{l}\text { Decreased health-related } \\
\text { QoL } \\
\text { Fatigue is common }\end{array}$ & $\begin{array}{l}\text { Inconsistent effects of LT4 on relatively } \\
\text { non-specific symptoms (importance of } \\
\text { ensuring an accurate diagnosis of } \\
\text { hypothyroidism) }\end{array}$ \\
\hline
\end{tabular}

a'Dealt with only briefly here, see chapters, "Levothyroxine and the Heart" and "Levothyroxine and Bone" of this book for a fuller account of the effects of hypothyroidism and LT4 on these organs, including discussion of the effects on cardiac outcomes. aVWS acquired Von Willebrand Syndrome, GFR glomerular filtration rate, $I G T$ impaired glucose tolerance, $Q o L$ quality of life. See text for references 
effects of treatment with LT4. Table 1 summarises these effects of LT4 replacement on important physiologic and metabolic processes in patients with hypothyroidism.

\subsection{Actions on Skeletal Muscle}

\subsubsection{Mechanisms}

Skeletal muscle is a major site of action of thyroid hormones. Active membrane transporters regulate the uptake of T4 and T3 from the extracellular space; once inside the cell, the T3 level is adjusted via deiodination of T4 and inactivation of T3, by Deiodinases 2 and 3, respectively [27-29]. Activation of the thyroid receptor drives multiple processes, from the initiation of muscle formation during early embryogenesis, to the differentiation of the various fast and slow skeletal muscle fibre phenotypes in adult muscle (high T3 levels favour fast-twitch type muscle fibres [30]), to the repair or replacement of damaged muscle fibres [27, 28]. Defects in these mechanisms, associated with changes in levels of thyroid hormones, may be implicated in the progression of myopathy states, including Duchenne muscular dystrophy, among others [31]. High levels of thyroid hormones increase energy utilisation, and decrease the efficiency of skeletal muscle, with opposite effects in hypothyroidism. Skeletal muscle accounts for up to half of an individual's body weight and changes in energy homeostasis in skeletal muscle exert an important influence on the overall metabolic rate $[27,28]$.

\subsubsection{Clinical Studies of Interest}

LT4 replacement therapy vs. no treatment has been shown to improve cardiopulmonary performance $\left(\mathrm{O}_{2}\right.$ uptake, minute ventilation, and heart rate) in subjects with subclinical hypothyroidism [32], although not all studies have shown this [33]. In another study, variation of LT4 doses to induce minor fluctuations of TSH around the reference range did not influence energy expenditure or body composition in patients with hypothyroidism [34]. Studies in euthyroid subjects showed variable effects of LT4 on muscle performance [35-37], consistent with the absence of indications for LT4 intervention in those without hypothyroidism.

\subsection{Effects on Lipid Profiles}

Thyroid hormones are metabolised in the liver, which influences their levels in the circulation [38]. T3 in the liver induces 3-hydroxy-3-methylglutaryl-coenzyme A (HMG-CoA, which initiates cholesterol synthesis), increases the synthesis and release of LDL receptors (enhancing LDL-cholesterol clearance), and stimulates the activity of lipoprotein lipase and apolipoprotein AV (which play a major role in triglyceride regulation) [39]. Thus, even mild hypothyroidism increases total 
cholesterol, LDL-cholesterol and, sometimes, triglycerides [40]. The administration of LT4 reduces serum cholesterol and other markers of dyslipidaemia in patients with varying degrees of hypothyroidism [40-44]. LT4 also reduced intrahepatic lipid content in an uncontrolled study in euthyroid subjects with non-alcoholic fatty liver disease and type 2 diabetes, suggesting a possible future role for LT4 in this population [45]. At present, LT4 does not have a recognised role in dyslipidaemia management of euthyroid individuals, however [46].

\subsection{Actions in Adipose Tissue}

Thyroid hormones have a powerful effect in stimulating thermogenesis in brown adipose tissue, to a much greater extent than that observed in white adipose tissue $[27,47]$. TSH correlates positively with body mass index, and overt hypothyroidism is associated with modest weight gain, which reverses with LT4 treatment; however, this weight loss may be associated more with loss of excess fluid than loss of fat mass [48]. A study in women with hypothyroidism showed that normalisation of TSH with LT4 did not affect body fat percentage significantly [49]. Changes in resting energy expenditure during LT4 treatment in humans are driven mainly by effects in skeletal muscle, as described above.

\subsection{Effects on Glucose Metabolism}

An association of autoimmune thyroid disease and type 1 diabetes mellitus has long been recognised $[50,51]$. Thyrotoxicosis was long believed to be the prime thyroid function abnormality associated with glucose intolerance and two-thirds of those found to be glucose intolerant while thyrotoxic were normal when retested after adequate antithyroid treatment; on the other hand, glucose intolerance persisted in the remainder [52]. Increased intestinal hexose absorption, decreased responsiveness to insulin, and increased glucose production have been proposed to mediate hyperglycaemic effects of thyrotoxicosis [50]. Further observations of insulin secretion/action defects in thyrotoxicosis were mainly accounted for by ageing [53, 54]. Normal insulin secretory function and adipocyte sensitivity in the face of a reduced number of adipocyte insulin receptors shifted the search for a mechanism toward the hepatocyte and resultant increased gluconeogenesis or changes in skeletal muscle glucose metabolism as the basis of glucose intolerance in thyrotoxic patients [55-57]. In summary, an increase in T3 activity as seen in overt hyperthyroidism, seems to drive increased production of glucose by the liver and may be associated with reduced insulin secretion from the pancreas, increasing the risk of glucose intolerance and diabetes [27].

Ironically, more recent research indicates that overt thyrotoxicosis is not necessarily the only influence on glucose intolerance and frank type 2 diabetes in genetically at-risk subjects. In fact, compared with euglycaemic, unrelated controls, those with new onset type 2 diabetes, impaired glucose intolerance (IGT) and relatives of type 2 
Fig. 2 Overview of some important effects of levothyroxine on glycaemia. ${ }^{\text {aEffects }}$ mediated via decreased apoptosis and enhanced growth and differentiation. (Compiled from information presented in Ref. [51])

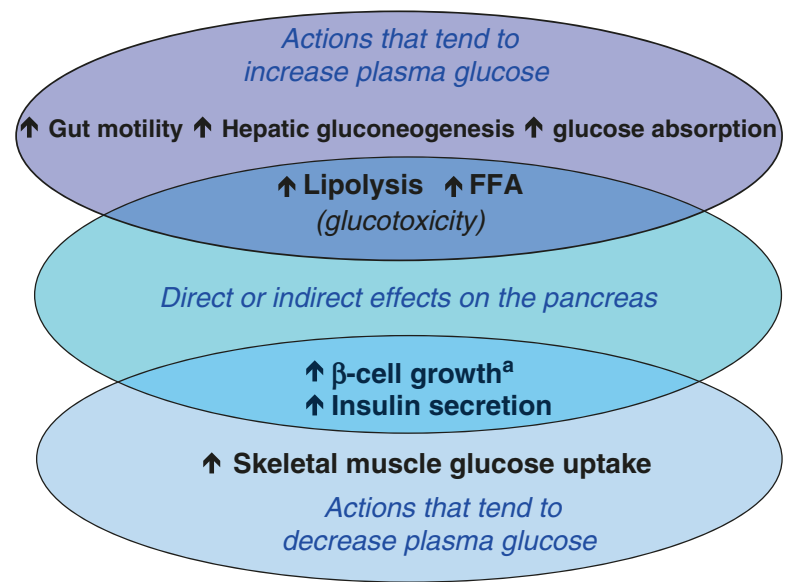

diabetes patients had higher FT4 and FT3 though all were within the expected range [58]. Cross-sectional observations showed that impaired fasting glucose (IFG) was associated with higher free T3 and FT3/FT4 ratios but lower FT4 than IGT, indicating that thyroid hormone levels may play differing roles in the development of different forms of dysglycaemia [59]. Further evidence of a direct influence of inadequate thyroid function on insulin resistance was reported in a group of athyrotic subjects, in the form of a negative correlation of FT4 and insulin during thyroid hormone withdrawal [60]. Another study showed that people with overt and subclinical hypothyroidism had similar severity of insulin resistance, each higher than in euthyroid controls, providing further evidence that hypothyroidism is an insulin-resistant state [61]. A study of 2,399 euthyroid, non-diabetic subjects showed that FT4 levels in the lower part of the normal range were associated with an increased risk of prediabetes [62], and other clinical data indicated that higher TSH levels, as found in hypothyroidism, increase the risk of developing type 2 diabetes [63].

Correction of subclinical hypothyroidism with LT4 has been shown to improve insulin resistance and/or control of blood glucose [42, 64-66]. A recent study showed that malabsorption of LT4 associated with concomitant calcium carbonate supplementation was associated with a decline in the quality of glycaemic control, which was reversed when the interval between LT4 and calcium supplementation was increased [67]. Practically, and reassuringly, exogenous LT4 does not seem to be associated with glucose tolerance issues, even at TSH-suppressive doses that result in prolonged subclinical thyrotoxicosis [68].

These studies leave us with some unanswered questions in regard to the mechanisms linking thyroid function and glucose intolerance. A recent review summarises six areas of mechanistic connections between the presence of thyrotoxicosis and abnormal glucose metabolism, and Fig. 2 summarises its main findings [51]. 


\subsection{Actions on Mood and Affect}

The hypothalamus is involved intimately in the complex relationships between thyroid hormone status and numerous aspects of metabolism and homeostasis, as described above. Changes in mood and affect are classically recognised symptoms of hypothyroidism [69]. LT4 administration to symptomatic hypothyroid subjects should improve mood and affect only if thyroid function provoked such symptoms. Unfortunately, recent observations in subclinical thyroid dysfunction alert us to the need to diagnose specific underlying thyroid abnormalities accurately, rather than empirically assuming a thyroid-deficient state. Subclinical hyperthyroidism has emerged as a more frequent underpinning of depression than mild thyroid failure [70-72], indicating that thyroid hormone replacement would not be universally appropriate for all situations where hypothyroidism is assumed to be present. Although some studies have reported very robust improvement in thyroid-specific symptoms when LT4 is used to titrate TSH into the normal range [73, 74], and other investigations seem to indicate that LT4 treated patients fare as well as appropriately selected controls [75], some investigators emphasise less than perfect resolution of symptoms with thyroid hormone replacement therapies [76-78].

Recently, a randomised, placebo-controlled trial in 60 patients with subclinical hypothyroidism did demonstrate a significant improvement in Beck Depression Inventory (BDI) scores in those randomised to LT4 therapy, while improvement was not observed in the placebo group [79]. The effect in the LT4 group was driven strongly by improvements in the somatic subscale of the BDI, with no significant improvement in the affect scale. A case-control study indicated that a population of women with hypothyroidism continued to have a higher prevalence of anxiety or depression than a control group of euthyroid women, even after correction of TSH using LT4 [80]. These findings have prompted some experts to propose individually derived cut-offs for TSH in the management of hypothyroidism with LT4, that is based on resolution of symptoms of depression [81]. These contradictory findings emphasise the current difficulties encountered in identifying specific symptoms truly due to thyroid hormone deficiency rather than the other, common, non-thyroid-related, symptoms that result in a major obstacle in the clinical assessment of self-reported complaints, especially in patients with chronic conditions [82]. Such symptoms would not be expected to respond to manipulation of the thyroid axis in those with normal thyroid function. Multiple alternative explanations for LT4-treated subjects' occasional unhappiness with their clinical outcomes have been reported extensively and potentially include independent effects of autoimmunity [83, 84], theoretical brain hypothyroidism with normal TSH [85], selection bias of subjects seeking health care [86], and awareness of having a chronic disease [87]. These and other explanations will be discussed in detail below.

Some have speculated that the documentation of biochemical hypothyroidism is less sensitive than clinical symptoms in identifying truly hypothyroid individuals who would benefit from LT4 replacement therapy. These anecdotal and testimonial reports seldom acknowledge the lack of effect of LT4 vs. placebo on the Hospital Anxiety/Depression Scale (HADS) and the Standard Form-36 (SF-36) in a 
randomised trial [88]. It seems clear that symptoms consistent with hypothyroidism in euthyroid individuals do not respond to (nor should they be treated with) LT4.

The relationship between hypothyroidism and the response of neuropsychiatric function to LT4 therapy has continued to generate interest in the potential application of LT4 treatment to correct these symptoms in euthyroid patients with psychiatric disorders. One study did not find a significant effect of LT4 on a validated instrument for quantifying symptoms of depression in people with bipolar disorder [89], while randomised [90] or observational [91] trials have indicated improved mood in euthyroid patients with bipolar disorder given an LT4 $300 \mu \mathrm{g} / \mathrm{day}$. It is difficult to disassociate effects on mood of LT4 per se from the adverse psychological impact of having a chronic thyroid condition, however [92]. LT4 is not indicated for this purpose, and these studies remain in the realm of research.

\subsection{Fatigue}

Patients with fatigue (a classic symptom of hypothyroidism) are reported to receive a lifetime diagnosis of depression or anxiety disorder much more frequently than others (45\% vs. 28\%) [93]. Similarly, tiredness, another non-specific "thyroid" symptom common in primary care is associated as frequently with chronic diseases such as diabetes, or anaemia, as with hypothyroidism, and more strongly associated with depression [94]. The correlation of symptoms consistent with hypothyroidism and actual, documentable hypothyroidism is poor [95]. The predictive value of individual symptoms in identifying hypothyroidism is substantially overlapping with symptoms offered by euthyroid individuals [96], and this lack of specificity is diminished even further by female gender and older age [97]. Persistent symptoms encountered in those on thyroid hormone replacement with well-controlled TSH levels and normal serum T3 levels have been demonstrated to be correlated more closely with comorbidities than thyroid function [98, 99], again highlighting the importance of assessing the entire patient rather than to assume that all complaints are thyroid related.

\subsection{Actions on Inflammation and Haemostasis}

Circulating levels of inflammatory cytokines were increased in hypothyroidism and reduced after treatment with LT4 in a randomised, placebo-controlled trial [100] and in an observational study [101]. In general, low levels of circulating thyroid hormone shift the haemostatic system to a hypocoagulable hyper-fibrinolytic state, with reduced Factors VIII, IX, and XI and von Willebrand factor (VWF) that are normalised on LT4 $[102,103]$. The coagulopathy of overt hypothyroidism has been referred to as an acquired von Willebrand syndrome (aVWS), seen in about onethird of these patients, with low VWF and FIII, with mucocutaneous bleeding that responds to desmopressin [104-106]. The incidence of aVWS may approach 33\% of those with overt hypothyroidism, may play a role of the menorrhagia observed in hypothyroidism, and may diminish the risk of venous thromboembolism (VTE) 
$[105,106]$. Subclinical hypothyroidism is paradoxically associated with a shift to a procoagulant state, with higher FVII, PAI-1, and tissue plasminogen activator (t-PA), which seem to normalise with 6 months of LT4 [107]. Thrombin-activatable fibrinolysis inhibitor (TAFI) levels are elevated, and global fibrinolytic capacity is lower, vs. control subjects in subclinical hypothyroidism $[108,109]$. Correction of TSH levels to normal using LT4 replacement correct these abnormalities [102, 110, 111].

Excess thyroid hormone activity results in a procoagulant state, with increased VWF, FVIII, fibrinogen, and D-dimer in subclinical hyperthyroidism and elevations in fibrinogen, fibronectin, VWF, thrombomodulin, and PAI-1, with decreased t-PA in overt, endogenous hyperthyroidism [103, 112-115]. The enhanced risk of VTE (deep vein thrombosis or pulmonary embolism) has been expertly summarised recently [103]. This underlying prothrombotic state interacts with the additional risk of atrial fibrillation/flutter to elevate the risk of ischaemic stroke [116]. Underlying mechanisms may include the presence of autoimmune disease, but unique observations from subjects with thyroid hormone resistance at the TR $\beta$ infer that the hyper-coagulation seen in thyrotoxicosis is a direct consequence of $\mathrm{T} 3$ action on levels of the coagulation factors described above [117]. Thyrotoxicosis induced by administration of LT4 to healthy volunteers and those with thyroid nodules also induces a procoagulant state, associated with increased levels of FVIII, FIX, FX, VWF, fibrinogen D-dimer, and PAI-1 with delayed fibrin clot lysis and a shortening of the APTT, but with an inconsistent impact on clot structure parameters potentially based on subtle mechanistic differences between endogenous and iatrogenic hyperthyroidism [118-121].

\subsection{Effects in the Kidney}

The hypothyroid state itself reduces renal function [122]. Administration of LT4 has been observed to improve renal function, in one study improving odds of progression and lowering the incidence of end-stage kidney disease by limiting the rate of decline in glomerular filtration rate [123]. In another randomised, placebocontrolled study, LT4 treatment reduced serum uric acid and excretion of albumin in a trial in patients with diabetic nephropathy and subclinical hypothyroidism, an effect consistent with a renoprotective effect [41].

\subsection{Effects on the Heart and in Bone}

Chapters, "Levothyroxine and the Heart" and "Levothyroxine and Bone" provide a description of the effects of LT4 in heart and bone, and only a brief summary is provided here in Table 1. 
Table 2 Summary of "strong" recommendations relating to the management of overt hypothyroidism from a guideline proposed by the American Thyroid Association

\begin{tabular}{|c|c|}
\hline Main therapy & $\begin{array}{l}\text { Monotherapy with LT4 adjusted using TSH; thyroid extracts are not } \\
\text { recommended. }\end{array}$ \\
\hline $\begin{array}{l}\text { Key goals of } \\
\text { therapy }\end{array}$ & $\begin{array}{l}\text { Normalise TSH (and improve other thyroid hormones), abolish symptoms } \\
\text { (including lipid abnormalities), avoid over treatment (iatrogenic } \\
\text { thyrotoxicosis). }\end{array}$ \\
\hline Starting dose & $\begin{array}{l}\text { Consider factors including weight, age, comorbidity, aetiology of thyroid } \\
\text { disease, starting TSH, desired TSH goal when deciding on starting LT4 } \\
\text { dose. }\end{array}$ \\
\hline $\begin{array}{l}\text { Mental health/ } \\
\text { behavioural issues }\end{array}$ & $\begin{array}{l}\text { Consider a mental health professional if psychosocial, behavioural, or } \\
\text { mental health symptoms do not respond adequately to LT4, or if these } \\
\text { issues impair management. }\end{array}$ \\
\hline Elderly patients & $\begin{array}{l}\text { Start with low dose, increase slowly (NB: ideal TSH may be higher in } \\
\text { older patients). }\end{array}$ \\
\hline Pregnancy & Use trimester-specific TSH reference ranges to guide therapy. ${ }^{a}$ \\
\hline Infants & $\begin{array}{l}\text { Treat as soon as hypothyroidism is confirmed; aim to move TSH to the } \\
\text { mid-to-lower half of the paediatric TSH reference range within } 2-4 \text { weeks. }\end{array}$ \\
\hline $\begin{array}{l}\text { Subgroups/ } \\
\text { comorbidities }\end{array}$ & $\begin{array}{l}\text { There is no evidence to support targeting low- or high-normal TSH for } \\
\text { subgroups such as those with obesity, depression, dyslipidaemia, or no } \\
\text { thyroid function. }\end{array}$ \\
\hline $\begin{array}{l}\text { Secondary } \\
\text { hypothyroidism }\end{array}$ & $\begin{array}{l}\text { Maintain the FT } 4 \text { in the upper half of the reference range (may be lower in } \\
\text { older patients or those with comorbidities). }\end{array}$ \\
\hline $\begin{array}{l}\text { Well-being and } \\
\text { quality of life }\end{array}$ & $\begin{array}{l}\text { Use general instruments + hypothyroidism-specific tools to evaluate } \\
\text { general well-being and quality of life during treatment. }\end{array}$ \\
\hline Euthyroid subjects & $\begin{array}{l}\text { Do not use LT4 in biochemically euthyroid people with hypothyroid-like } \\
\text { symptoms or for the management of obesity, depression, urticaria, or } \\
\text { dyslipidaemia }\end{array}$ \\
\hline $\begin{array}{l}\text { Thyroid hormone } \\
\text { abuse }\end{array}$ & $\begin{array}{l}\text { Withdraw thyroid hormones from patients with factitious thyrotoxicosis } \\
\text { and refer for education and/or psychological support }\end{array}$ \\
\hline LT4 + T3 therapy & Insufficient clinical evidence to support a routine-use recommendation ${ }^{b}$ \\
\hline $\begin{array}{l}\text { Nutraceuticals and } \\
\text { supplements }\end{array}$ & $\begin{array}{l}\text { Not supported in hypothyroidism management (pharmacological doses of } \\
\text { iodine may exacerbate underlying thyroid pathology) }\end{array}$ \\
\hline $\begin{array}{l}\text { Hospitalised/not } \\
\text { critically ill patients }\end{array}$ & $\begin{array}{l}\text { Consider starting or adjusting oral LT4 (consider temporary use of i.v. LT4 } \\
\text { if necessary), based on normalisation of TSH; exclude adrenal } \\
\text { insufficiency }\end{array}$ \\
\hline Myxoedema coma & $\begin{array}{l}\text { Start with i.v. LT4 (+standard management for coma including } \\
\text { glucocorticoids), with starting dose depending on age and comorbidities, } \\
\text { and switch to oral LT4 when possible. Improved mental status and } \\
\text { improved cardiac/pulmonary function are key early measurements, follow } \\
\text { thyroid hormones thereafter }\end{array}$ \\
\hline $\begin{array}{l}\text { "Nonthyroidal } \\
\text { illness syndrome" }\end{array}$ & LT4 is not recommended for hospitalised patients with this condition. \\
\hline
\end{tabular}

Recommendations are abstracted from Ref. [125]. They have been paraphrased for brevity, and combined in some cases. Only strong recommendations relating to the use of LT4 are included here: see the full guideline for details

aSee chapter, "Levothyroxine in Pregnancy" for a description of hypothyroidism management in pregnancy. GI gastrointestinal, LT4 levothyroxine, TSH thyrotropin, thyroid-stimulating hormone ${ }^{\mathrm{b}}$ Evidence for LT4 + T3 combination therapy is discussed later in this chapter 


\section{Evidence-Based Guidelines for the Management of Hypothyroidism}

\subsection{Current Status of Evidence-Based Guidelines}

The American Thyroid Association (ATA) has been publishing regular guidance on the management of thyroid disease since its recommendations on nomenclature for goitre in 1931 [124]. The most recent ATA guideline for the management of hypothyroidism (2014) considered 64 questions relating to the care of these patients, grouped under 24 topics [125]. An overview of its strong recommendations with regard to the management of overt hypothyroidism in adults is given in Table 2 . These guidelines emphasise the key role of monotherapy with LT4 (the use of thyroid extracts is not supported) in the management of hypothyroidism, due mainly to its proven efficacy and safety profile, long half-life and low cost. The level of thyrotropin is used to guide therapy in almost all circumstances, rather than other thyroid hormones, or symptoms of hypothyroidism. The therapeutic use of LT4 for other conditions, such as obesity, psychiatric conditions, and dyslipidaemia, is not supported and such uses remain an area for research (see above). A guideline from the UK National Institute for Health and Care Excellence (2019) provided similar recommendations [126].

The 2014 ATA guidance did not address the issue of managing subclinical hypothyroidism. Additional information is now available from the TRUST study, a large, prospective, randomised, controlled trial of LT4 in a population likely to be enriched with people with subclinical hypothyroidism $(\mathrm{TSH}>4.6 \mathrm{mIU} / \mathrm{L}$ with normal FT4) [127]. A total of 737 patients aged $>65$ years were recruited and the primary outcome parameter was QoL (Thyroid-Related Quality of Life Patient Reported Outcome [ThyPro] subscales for hypothyroid symptoms score and tiredness score). Neither thyroid symptoms nor tiredness scores were changed significantly in the LT4 or placebo groups by 12 months [127]. Reassuringly, there were no adverse effects of LT4. Although the quality of this trial warranted publication in a premier medical journal, the use of non-age-adjusted TSH at entry likely led to the inclusion of many functionally euthyroid subjects, rendering demonstration of a therapeutic effect of LT4 very unlikely. Although the TSH levels in those on LT4 were reduced impressively, one-quarter of subjects were asymptomatic. The mean baseline TSH in both groups was below the age expected $97.5^{\text {th }}$ percentile (normal) of euthyroid, antibody negative individuals observed for the US population [128]. Additionally, the TSH levels of the placebo group had also normalised in an unknown but significant portion with no intervention, further reducing the potential for demonstrating a therapeutic impact of LT4.

A recent (2018), high quality meta-analysis of 21 randomised, placebocontrolled trials of LT4 ( $N=2192$ subclinically hypothyroid adults) focussed on QoL and thyroid-related symptoms and confirmed a lack of improvement with 
LT4 in these subjective endpoints [129]. A guideline from the European Thyroid Association (ETA) based on this meta-analysis recommended that a trial of LT4 should be considered in younger ( $<65$ years) subjects with symptoms reminiscent of hypothyroidism with TSH that is elevated, but $<10 \mathrm{mIU} / \mathrm{L}$ [130]. LT4 can be withdrawn if symptoms have not resolved after normalisation of the thyrotropin level. Younger subjects with thyrotropin $>10 \mathrm{mIU} / \mathrm{L}$ should receive LT4 whether or not they have symptoms [130]. Another international expert group concluded that few patients with subclinical hypothyroidism would be likely to benefit from treatment with LT4 [131].

Another meta-analysis and independent review provided guidance on the need for confirmation of the diagnosis of mild thyroid failure/subclinical hypothyroidism in non-pregnant adults [132]. TSH and FT4 should be re-measured in 1-3 months when TSH is $4.5-14.9 \mathrm{mIU} / \mathrm{L}$, and in $1-2$ weeks when TSH is $\geq 15 \mathrm{mIU} / \mathrm{L}$. Confirmation of the elevated TSH is considered essential in establishing the diagnosis of subclinical hypothyroidism although this is not a guarantee of persistent thyroid failure [127, 133]. Additionally, LT4 may be considered for reduced risk of progression to overt hypothyroidism and adverse cardiovascular outcomes for patients aged $>65$ years with TSH $>7 \mathrm{mIU} / \mathrm{L}$, and offered when TSH is persistently over $10 \mathrm{mIU} / \mathrm{L}$. Recommendations for individuals aged $<65$ years are more liberal and recommend measurement of anti-TPO antibodies when the TSH is $4.5-6.9 \mathrm{mIU} / \mathrm{L}$, with annual follow-up. LT4 treatment would be considered when multiple symptoms are present, TPO antibodies are positive, TSH is increasing, pregnancy is anticipated, or goitre is present. LT4 therapy is recommended in this age group when TSH is persistently $>7.0 \mathrm{mIU} / \mathrm{L}$ [132].

\subsection{Levothyroxine Monotherapy, or Levothyroxine Plus Triiodothyronine, for Hypothyroidism}

Loss-of-function polymorphisms in deiodinases have been proposed to contribute to failure of thyrotropin-guided LT4 therapy to completely abolish symptoms of hypothyroidism in some patients, due to insufficient provision of T3 [134, 135]. This has stimulated interest (and use to this day) in LT4-levotriiodothyronine (liothyronine, LT3) combination therapy, or thyroid extracts (which are not supported by any guidelines), in these patients $[135,136]$. The results of trials comparing LT4-LT3 combinations with LT4 monotherapy, or meta-analyses of these trials, have been inconsistent, without demonstrating convincing or consistent benefit for combination therapy $[135,137,138]$. In addition, the short plasma half-life of LT3 (hours), compared with that of LT4 (days) does not support straightforward once-daily administration of these combinations. Accordingly, there is currently no accepted role for the use of LT3 in the management of hypothyroidism [125, $135,137]$. 
It has been suggested that more trials are needed, in patients with reduced sensitivity to thyroid hormones [137]. Alternatively, differences in initial residual thyroid function between patients may have introduced variability into the results of these trials [139]. Although there is support in a European guideline for a trial of LT4-LT3 therapy in individuals with persistent hypothyroid-like symptoms on LT4 after exclusion of other possible causes [140], further research will be needed before this approach becomes part of the routine care of hypothyroidism.

\subsection{Barriers to Optimal Care of Patients with Hypothyroidism}

\subsubsection{The Impact of the Diagnosis Itself}

Diagnostic labelling influences individual patient's self-reported health results as illustrated in a recent report derived from the HUNT study which asked subjects to rate their perception of their health [141]. Data on thyroid function at entry were available to researchers only. Most (at least 75\%) of the general population and subjects unaware of their thyroid dysfunction reported their health as good; however, only half of those aware of a diagnosis of thyroid dysfunction reported good health. Increasing age, lower education, smoking, low self-esteem, underweight, overweight, or obese and long-term illness/injury-but not thyroid function-predicted lower self-reported health.

\subsubsection{Avoiding over Diagnosis}

Who would typically be evaluated with thyroid function testing in a primary care practice and potentially labelled as hypothyroid? According to a study in the primary care setting, those referred for thyroid function tests have high rates of psychological stress and low (no) correlation of typical thyroid symptoms and thyroid test results [142]. The authors expressed concern that a mild TSH elevation might result in reflexive LT4 initiation. This of course assumes that the symptoms are truly due to hypothyroidism and a search for alternative explanations ends. I would point out that failure of LT4 intervention to cure these likely non-thyroid symptoms would not only disappoint our now-labelled patient, but might also distract the treating physician from the potential of psychiatric morbidity and initiate a quest for alternative thyroid solutions rather than providing the patient with the help they really need.

Once confidence in a diagnosis of hypothyroidism is established, further attempts to satisfy subjects treated with LT4 who continue to report symptoms consistent with hypothyroidism has led to the practice of finely titrating the TSH into specific tertiles of the expected range with small LT4 dose adjustments. Two excellent 
prospective controlled studies have used validated measures of health-related quality of life (HR-QoL) and cognition to demonstrate little or no benefit from this approach $[143,144]$. Most importantly, patients were unable to correctly identify whether they had received the lower, medium, or higher dose, but associated the higher dose with a perception of greater efficacy [144].

\section{Conclusions}

Thyroid hormones are tightly integrated within the development, homeostasis, and repair of numerous tissues in the body, including the regulation of the HPT axis itself. Accordingly, hypothyroidism disturbs multiple functions within the body. Hormone replacement with LT4 can reverse many symptoms of hypothyroidism, including reduced energy expenditure, dyslipidaemia, and disturbances of diverse functions, including haemostasis and mood. Not all patients feel completely well on optimised LT4 therapy, however, often for various non-thyroid-related reasons. Variations in sensitivity to thyroid hormones, arising for example, in variations in genes for the deiodinases that convert LT4 to T3 within target tissues or in thyroid hormone transporters, may contribute to this phenomenon, and this remains a subject for future research. Monotherapy with LT4, optimised according to a normalised serum TSH level, remains the preferred treatment for hypothyroidism recommended by current major guidelines in this area.

\section{References}

1. Pirahanchi Y, Jialal I. Physiology, thyroid stimulating hormone (TSH). StatPearls [Internet]. Available at https://www.ncbi.nlm.nih.gov/books/NBK499850/. Accessed Jul 2020.

2. Mariotti S, Beck-Peccoz P. Physiology of the hypothalamic-pituitary-thyroid axis. Endotext [Internet]. Available at https://www.ncbi.nlm.nih.gov/books/NBK278958/. Accessed Jul 2020.

3. Hoermann R. Homeostatic control of the thyroid-pituitary axis: perspectives for diagnosis and treatment. Front Endocrinol (Lausanne). Nov 2015. Available at https://www.frontiersin. org/articles/10.3389/fendo.2015.00177/full. Accessed Jul 2020

4. Köhrle J. The colorful diversity of thyroid hormone metabolites. Eur Thyroid J. 2019;8:115-29.

5. Bianco AC, da Conceição RR. The deiodinase trio and thyroid hormone signaling. Methods Mol Biol. 2018;1801:67-83.

6. Werneck de Castro JP, Fonseca TL, Ueta CB, et al. Differences in hypothalamic type 2 deiodinase ubiquitination explain localized sensitivity to thyroxine. J Clin Invest. 2015;125:769-81.

7. Gullo D, Latina A, Frasca F, Le Moli R, Pellegriti G, Vigneri R. Levothyroxine monotherapy cannot guarantee euthyroidism in all athyreotic patients. PLoS One. 2011;6:e22552.

8. Ito M, Miyauchi A, Morita S, et al. TSH-suppressive doses of levothyroxine are required to achieve preoperative native serum triiodothyronine levels in patients who have undergone total thyroidectomy. Eur J Endocrinol. 2012;167:373-8.

9. Hennessey JV, Evaul JE, Tseng YC, Burman KD, Wartofsky L. L-thyroxine dosage: a reevaluation of therapy with contemporary preparations. Ann Intern Med. 1986;105:11-5. 
10. Fish LH, Schwartz HL, Cavanaugh J, Steffes MW, Bantle JP, Oppenheimer JH. Replacement dose, metabolism, and bioavailability of levothyroxine in the treatment of hypothyroidism. Role of triiodothyronine in pituitary feedback in humans. N Engl J Med. 1987;316:764-70.

11. Liewendahl K, Helenius T, Lamberg BA, Mähönen H, Wägar G. Free thyroxine, free triiodothyronine, and thyrotropin concentrations in hypothyroid and thyroid carcinoma patients receiving thyroxine therapy. Acta Endocrinol (Copenh). 1987;116:418-24.

12. Jonklaas J, Davidson B, Bhagat S, Soldin SJ. Triiodothyronine levels in athyreotic individuals during levothyroxine therapy. JAMA. 2008;299:769-77.

13. Hoermann R, Midgley JE, Larisch R, Dietrich JW. Integration of peripheral and glandular regulation of triiodothyronine production by thyrotropin in untreated and thyroxine-treated subjects. Horm Metab Res. 2015;47:674-80.

14. Leow MK, Goede SL. The homeostatic set point of the hypothalamus-pituitary-thyroid axis-maximum curvature theory for personalized euthyroid targets. Theor Biol Med Model. 2014;11:35.

15. Anyetei-Anum CS, Roggero VR, Allison LA. Thyroid hormone receptor localization in target tissues. J Endocrinol. 2018;237:R19-34.

16. Ortiga-Carvalho TM, Sidhaye AR, Wondisford FE. Thyroid hormone receptors and resistance to thyroid hormone disorders. Nat Rev Endocrinol. 2014;10:582-91.

17. Singh BK, Yen PM. A clinician's guide to understanding resistance to thyroid hormone due to receptor mutations in the TR $\alpha$ and TR $\beta$ isoforms. Clin Diab Endocrinol. 2017;3:8.

18. Nikrodhanond AA, Ortiga-Carvalho TM, Shibusawa N, et al. Dominant role of thyrotropinreleasing hormone in the hypothalamic-pituitary-thyroid axis. J Biol Chem. 2006;281:5000-7.

19. Menezes-Ferreira MM, Petrick PA, Weintraub BD. Regulation of thyrotropin (TSH) bioactivity by TSH-releasing hormone and thyroid hormone. Endocrinology. 1986;118:2125-30.

20. Prummel MF, Brokken LJ, Wiersinga WM. Ultra short-loop feedback control of thyrotropin secretion. Thyroid. 2004;14:825-9.

21. Sheehan MT. Biochemical testing of the thyroid: TSH is the best and, oftentimes, only test needed —a review for primary care. Clin Med Res. 2016;14:83-92.

22. Brown SJ, Bremner AP, Hadlow NC, et al. The log TSH-free T4 relationship in a communitybased cohort is nonlinear and is influenced by age, smoking and thyroid peroxidase antibody status. Clin Endocrinol (Oxf). 2016;85:789-96.

23. Hoermann R, Eckl W, Hoermann C, Larisch R. Complex relationship between free thyroxine and TSH in the regulation of thyroid function. Eur J Endocrinol. 2010;162:1123-9.

24. Rothacker KM, Brown SJ, Hadlow NC, Wardrop R, Walsh JP. Reconciling the log-linear and non-log-linear nature of the tsh-free 4 relationship: intra-individual analysis of a large population. J Clin Endocrinol Metab. 2016;101:1151-8.

25. Clark PM, Holder RL, Haque SM, Hobbs FD, Roberts LM, Franklyn JA. The relationship between serum TSH and free T4 in older people. Postgrad Med J. 2012;88:668-70.

26. Razvi S, Bhana S, Mrabeti S. Challenges in interpreting thyroid stimulating hormone results in the diagnosis of thyroid dysfunction. J Thyroid Res. 2019;2019:4106816.

27. Cicatiello AG, Di Girolamo D, Dentice M. Metabolic effects of the intracellular regulation of thyroid hormone: old players, new concepts. Front Endocrinol (Lausanne). 2018;9:474.

28. Salvatore D, Simonides WS, Dentice M, Zavacki AM, Larsen PR. Thyroid hormones and skeletal muscle-new insights and potential implications. Nat Rev Endocrinol. 2014;10:206-14.

29. Marsili A, Tang D, Harney JW, et al. Type II iodothyronine deiodinase provides intracellular 3,5,3'-triiodothyronine to normal and regenerating mouse skeletal muscle. Am J Physiol Endocrinol Metab. 2011;301:E818-24.

30. Larsson L, Li X, Teresi A, Salviati G. Effects of thyroid hormone on fast- and slow-twitch skeletal muscles in young and old rats. J Physiol. 1994;481:149-61.

31. Bloise FF, Oliveira TS, Cordeiro A, Ortiga-Carvalho TM. Thyroid hormones play role in sarcopenia and myopathies. Front Physiol. 2018;9:560. 
32. Mainenti MR, Vigário PS, Teixeira PF, Maia MD, Oliveira FP, Vaisman M. Effect of levothyroxine replacement on exercise performance in subclinical hypothyroidism. J Endocrinol Investig. 2009;32:470-3.

33. Caraccio N, Natali A, Sironi A, et al. Muscle metabolism and exercise tolerance in subclinical hypothyroidism: a controlled trial of levothyroxine. J Clin Endocrinol Metab. 2005;90:4057-62.

34. Samuels MH, Kolobova I, Niederhausen M, Purnell JQ, Schuff KG. Effects of altering levothyroxine dose on energy expenditure and body composition in subjects treated with LT4. J Clin Endocrinol Metab. 2018;103:4163-75.

35. Rosenbaum M, Goldsmith RL, Haddad F, et al. Triiodothyronine and leptin repletion in humans similarly reverse weight-loss-induced changes in skeletal muscle. Am J Physiol Endocrinol Metab. 2018;315:E771-9.

36. Johannsen DL, Galgani JE, Johannsen NM, Zhang Z, Covington JD, Ravussin E. Effect of short-term thyroxine administration on energy metabolism and mitochondrial efficiency in humans. PLoS One. 2012;7:e40837.

37. Dubois S, Abraham P, Rohmer V, et al. Thyroxine therapy in euthyroid patients does not affect body composition or muscular function. Thyroid. 2008;18:13-9.

38. Mullur R, Liu YY, Brent GA. Thyroid hormone regulation of metabolism. Physiol Rev. 2014;94:355-82.

39. Rizos CV, Elisaf MS, Liberopoulos EN. Effects of thyroid dysfunction on lipid profile. Open Cardiovasc Med J. 2011;5:76-84.

40. dos Santos Teixeira PDF, Reuters VS, Ferreira MM, et al. Lipid profile in different degrees of hypothyroidism and effects of levothyroxine replacement in mild thyroid failure. Transl Res. 2008;151:224-31.

41. Liu P, Liu R, Chen X, et al. Can levothyroxine treatment reduce urinary albumin excretion rate in patients with early type 2 diabetic nephropathy and subclinical hypothyroidism? A randomized double-blind and placebo-controlled study. Curr Med Res Opin. 2015;31:2233-40.

42. Kowalska I, Borawski J, Nikołajuk A, et al. Insulin sensitivity, plasma adiponectin and sICAM-1 concentrations in patients with subclinical hypothyroidism: response to levothyroxine therapy. Endocrine. 2011;40:95-101.

43. Monzani F, Caraccio N, Kozàkowà M, et al. Effect of levothyroxine replacement on lipid profile and intima-media thickness in subclinical hypothyroidism: a double-blind, placebocontrolled study. J Clin Endocrinol Metab. 2004;89:2099-106.

44. Caraccio N, Ferrannini E, Monzani F. Lipoprotein profile in subclinical hypothyroidism: response to levothyroxine replacement, a randomized placebo-controlled study. J Clin Endocrinol Metab. 2002;87:1533-8.

45. Bruinstroop E, Dalan R, Cao Y, et al. Low-dose levothyroxine reduces intrahepatic lipid content in patients with type 2 diabetes mellitus and NAFLD. J Clin Endocrinol Metab. 2018;103:2698-706.

46. Bantle JP, Hunninghake DB, Frantz ID, Kuba K, Mariash CN, Oppenheimer JH. Comparison of effectiveness of thyrotropin-suppressive doses of D- and L-thyroxine in treatment of hypercholesterolemia. Am J Med. 1984;77:475-81.

47. Sanyal D, Raychaudhuri M. Hypothyroidism and obesity: an intriguing link. Indian J Endocrinol Metab. 2016;20:554-7.

48. Santini F, Marzullo P, Rotondi M, et al. Mechanisms in endocrinology: the crosstalk between thyroid gland and adipose tissue: signal integration in health and disease. Eur J Endocrinol. 2014;171:R137-52.

49. Bakiner O, Bozkirli E, Ersozlu Bozkirli ED, Ozsahin K. Correction of hypothyroidism seems to have no effect on body fat. Int J Endocrinol. 2013;2013:576794.

50. Mouradian M, Abourizk N. Diabetes mellitus and thyroid disease. Diabetes Care. 1983;6:512-20.

51. Nishi M. Diabetes mellitus and thyroid diseases. Diabetol Int. 2018;9:108-12. 
52. Maxon HR, Kreines KW, Goldsmith RE, Knowles HC Jr. Long-term observations of glucose tolerance in thyrotoxic patients. Arch Intern Med. 1975;135:1477-80.

53. Ikeda T, Fujiyama K, Hoshino T, Takeuchi T, Mashiba H, Tominaga M. Oral and intravenous glucose-induced insulin secretion in hyperthyroid patients. Metabolism. 1990;39:633-7.

54. Komiya I, Yamada T, Sato A, Koizumi Y, Aoki T. Effects of antithyroid drug therapy on blood glucose, serum insulin, and insulin binding to red blood cells in hyperthyroid patients of different ages. Diabetes Care. 1985;8:161-8.

55. Taylor R, McCulloch AJ, Zeuzem S, Gray P, Clark F, Alberti KG. Insulin secretion, adipocyte insulin binding and insulin sensitivity in thyrotoxicosis. Acta Endocrinol (Copenh). 1985;109:96-103.

56. Jap TS, Ho LT, Won JG. Insulin secretion and sensitivity in hyperthyroidism. Horm Metab Res. 1989;21:261-6.

57. Dimitriadis GD, Raptis SA. Thyroid hormone excess and glucose intolerance. Exp Clin Endocrinol Diabetes. 2001;109(Suppl 2):S225-39.

58. Lambadiari V, Mitrou P, Maratou E, et al. Thyroid hormones are positively associated with insulin resistance early in the development of type 2 diabetes. Endocrine. 2011;39: $28-32$.

59. Jing S, Xiaoying D, Ying X, et al. Different levels of thyroid hormones between impaired fasting glucose and impaired glucose tolerance: free $\mathrm{T} 3$ affects the prevalence of impaired fasting glucose and impaired glucose tolerance in opposite ways. Clin Endocrinol (Oxf). 2014;80:890-8.

60. Owecki M, El Ali Z, Nikisch E, Sowiński J. Serum insulin levels and the degree of thyroid dysfunction in hypothyroid women. Neuro Endocrinol Lett. 2008;29:137-40.

61. Maratou E, Hadjidakis DJ, Kollias A, et al. Studies of insulin resistance in patients with clinical and subclinical hypothyroidism. Eur J Endocrinol. 2009;160:785-90.

62. Kim SW, Jeon JH, Moon JS, et al. Low-normal free thyroxine levels in euthyroid male are associated with prediabetes. Diabetes Metab J. 2019;43:718-26.

63. Chaker L, Ligthart S, Korevaar TI, et al. Thyroid function and risk of type 2 diabetes: a population-based prospective cohort study. BMC Med. 2016;14:150.

64. Velija-Asimi Z, Karamehic J. The effects of treatment of subclinical hypothyroidism on metabolic control and hyperinsulinemia. Med Arh. 2007;61:20-1.

65. Stanicka S, Vondra K, Pelikanova T, Vlcek P, Hill M, Zamrazil V. Insulin sensitivity and counter-regulatory hormones in hypothyroidism and during thyroid hormone replacement therapy. Clin Chem Lab Med. 2005;43:715-20.

66. Roth J, Müller N, Kuniss N, Wolf G, Müller UA. Association between glycaemic control and the intake of thiazide diuretics, beta blockers and levothyroxine in people without diabetes. Exp Clin Endocrinol Diabetes. 2019; https://doi.org/10.1055/a-0919-4525.

67. Morini E, Catalano A, Lasco A, Morabito N, Benvenga S. L-thyroxine malabsorption due to calcium carbonate impairs blood pressure, total cholesterolemia, and fasting glycemia. Endocrine. 2019;64:284-92.

68. Heemstra KA, Smit JW, Eustatia-Rutten CF, et al. Glucose tolerance and lipid profile in longterm exogenous subclinical hyperthyroidism and the effects of restoration of euthyroidism, a randomised controlled trial. Clin Endocrinol (Oxf). 2006;65:737-44.

69. Hennessey JV, Scherger JE. Evaluating and treating the patient with hypothyroid disease. J Fam Pract. 2007;56(8 Suppl Hot Topics):S31-9.

70. Almeida C, Brasil MA, Costa AJ, et al. Subclinical hypothyroidism: psychiatric disorders and symptoms. Braz J Psychiatry. 2007;29:157-9.

71. Blum MR, Wijsman LW, Virgini VS, et al. Subclinical thyroid dysfunction and depressive symptoms among the elderly: a prospective cohort study. Neuroendocrinology. 2016;103:291-9.

72. Hong JW, Noh JH, Kim DJ. Association between subclinical thyroid dysfunction and depressive symptoms in the Korean adult population: the 2014 Korea National Health and Nutrition Examination Survey. PLoS One. 2018;13:e0202258. 
73. Singh R, Tandon A, Gupta SK, Saroja K. Optimal levothyroxine replacement adequately improves symptoms of hypothyroidism; residual symptoms need further evaluation for other than hypothyroidism causation. Indian J Endocrinol Metab. 2017;21:830-5.

74. Brokhin M, Danzi S, Klein I. Assessment of the adequacy of thyroid hormone replacement therapy in hypothyroidism. Front Endocrinol (Lausanne). 2019;10:631.

75. Peterson SJ, McAninch EA, Bianco AC. Is a normal TSH synonymous with "euthyroidism" in levothyroxine monotherapy? J Clin Endocrinol Metab. 2016;101:4964-73.

76. Saravanan P, Chau WF, Roberts N, Vedhara K, Greenwood R, Dayan CM. Psychological well-being in patients on 'adequate' doses of 1-thyroxine: results of a large, controlled community-based questionnaire study. Clin Endocrinol (Oxf). 2002;57:577-85.

77. Quinque EM, Villringer A, Kratzsch J, Karger S. Patient-reported outcomes in adequately treated hypothyroidism-insights from the German versions of ThyDQoL, ThySRQ and ThyTSQ. Health Qual Life Outcomes. 2013;11:68.

78. Peterson SJ, Cappola AR, Castro MR, et al. An online survey of hypothyroid patients demonstrates prominent dissatisfaction. Thyroid. 2018;28:707-21.

79. Najafi L, Malek M, Hadian A, Ebrahim Valojerdi A, Khamseh ME, Aghili R. Depressive symptoms in patients with subclinical hypothyroidism - the effect of treatment with levothyroxine: a double-blind randomized clinical trial. Endocr Res. 2015;40:121-6.

80. Romero-Gómez B, Guerrero-Alonso P, Carmona-Torres JM. Mood disorders in levothyroxinetreated hypothyroid women. Int J Environ Res Public Health. 2019;16:4776.

81. Talaei A, Rafee N, Rafei F, Chehrei A. TSH cut off point based on depression in hypothyroid patients. BMC Psychiatry. 2017;17:327.

82. Stewart AL, Greenfield S, Hays RD, et al. Functional status and well-being of patients with chronic conditions. Results from the medical outcomes study [published correction appears in JAMA 1989 Nov 10;262(18):2542]. JAMA. 1989;262:907-13.

83. Carta MG, Loviselli A, Hardoy MC, et al. The link between thyroid autoimmunity (antithyroid peroxidase autoantibodies) with anxiety and mood disorders in the community: a field of interest for public health in the future. BMC Psychiatry. 2004;4:25.

84. Groer MW, Vaughan JH. Positive thyroid peroxidase antibody titer is associated with dysphoric moods during pregnancy and postpartum. J Obstet Gynecol Neonatal Nurs. 2013;42:E26-32.

85. Panicker V, Saravanan P, Vaidya B, et al. Common variation in the DIO2 gene predicts baseline psychological well-being and response to combination thyroxine plus triiodothyronine therapy in hypothyroid patients. J Clin Endocrinol Metab. 2009;94:1623-9.

86. Kong WM, Sheikh MH, Lumb PJ, et al. A 6-month randomized trial of thyroxine treatment in women with mild subclinical hypothyroidism. Am J Med. 2002;112:348-54.

87. Ladenson PW. Psychological wellbeing in patients. Clin Endocrinol (Oxf). 2002;57:575-6.

88. Pollock MA, Sturrock A, Marshall K, et al. Thyroxine treatment in patients with symptoms of hypothyroidism but thyroid function tests within the reference range: randomised double blind placebo controlled crossover trial. BMJ. 2001;323:891-5.

89. Stamm TJ, Lewitzka U, Sauer C, et al. Supraphysiologic doses of levothyroxine as adjunctive therapy in bipolar depression: a randomized, double-blind, placebo-controlled study. J Clin Psychiatry. 2014;75:162-8.

90. Bauer M, Berman S, Stamm T, et al. Levothyroxine effects on depressive symptoms and limbic glucose metabolism in bipolar disorder: a randomized, placebo-controlled positron emission tomography study. Mol Psychiatry. 2016;21:229-36.

91. Bauer M, London ED, Rasgon N, et al. Supraphysiological doses of levothyroxine alter regional cerebral metabolism and improve mood in bipolar depression. Mol Psychiatry. 2005;10:456-69.

92. Samuels MH, Kolobova I, Smeraglio A, Peters D, Janowsky JS, Schuff KG. The effects of levothyroxine replacement or suppressive therapy on health status, mood, and cognition. J Clin Endocrinol Metab. 2014;99:843-51. 
93. Cathébras PJ, Robbins JM, Kirmayer LJ, Hayton BC. Fatigue in primary care: prevalence, psychiatric comorbidity, illness behavior, and outcome. J Gen Intern Med. 1992;7:276-86.

94. Stadje R, Dornieden K, Baum E, et al. The differential diagnosis of tiredness: a systematic review. BMC Fam Pract. 2016;17:147.

95. Canaris GJ, Steiner JF, Ridgway EC. Do traditional symptoms of hypothyroidism correlate with biochemical disease? J Gen Intern Med. 1997;12:544-50.

96. Canaris GJ, Manowitz NR, Mayor G, Ridgway EC. The Colorado thyroid disease prevalence study. Arch Intern Med. 2000;160:526-34.

97. Carlé A, Pedersen IB, Knudsen N, et al. Hypothyroid symptoms fail to predict thyroid insufficiency in old people: a population-based case-control study. Am J Med. 2016;129: 1082-92.

98. Wouters H. Abstract OR34-1 and oral presentation at: the endocrine society annual meeting, Chicago, USA, 17-20 Mar 2018.

99. Massolt ET, van der Windt M, Korevaar TI, et al. Thyroid hormone and its metabolites in relation to quality of life in patients treated for differentiated thyroid cancer. Clin Endocrinol (Oxf). 2016;85:781-8.

100. Krysiak R, Okopien B. The effect of levothyroxine and selenomethionine on lymphocyte and monocyte cytokine release in women with Hashimoto's thyroiditis. J Clin Endocrinol Metab. 2011;96:2206-15.

101. Bilgir O, Bilgir F, Calan M, Calan OG, Yuksel A. Comparison of pre- and post-levothyroxine high-sensitivity c-reactive protein and fetuin-a levels in subclinical hypothyroidism. Clinics (Sao Paulo). 2015;70:97-101.

102. Gullo S, Sav H, Kamel N. Effects of levothyroxine treatment on biochemical and hemostasis parameters in patients with hypothyroidism. Eur J Endocrinol. 2005;152:355-61.

103. Elbers LPB, Fliers E, Cannegieter SC. The influence of thyroid function on the coagulation system and its clinical consequences. J Thromb Haemost. 2018;16:634-45.

104. Manfredi E, van Zaane B, Gerdes VE, Brandjes DP, Squizzato A. Hypothyroidism and acquired von Willebrand's syndrome: a systematic review. Haemophilia. 2008;14:423-33.

105. Debeij J, van Zaane B, Dekkers OM, et al. High levels of procoagulant factors mediate the association between free thyroxine and the risk of venous thrombosis: the MEGA study. J Thromb Haemost. 2014;12:839-46.

106. van Zaane B, Squizzato A, Huijgen R, et al. Increasing levels of free thyroxine as a risk factor for a first venous thrombosis: a case-control study. Blood. 2010;115:4344-9.

107. Lupoli R, Di Minno MN, Tortora A, et al. Primary and secondary hemostasis in patients with subclinical hypothyroidism: effect of levothyroxine treatment. J Clin Endocrinol Metab. 2015;100:2659-65.

108. Guldiken S, Demir M, Turgut B, Altun BU, Arikan E, Kara M. Global fibrinolytic capacity in patients with subclinical hypothyroidism. Endocr J. 2005;52:363-7.

109. Akinci B, Comlekci A, Ali Ozcan M, et al. Elevated thrombin activatable fibrinolysis inhibitor (TAFI) antigen levels in overt and subclinical hypothyroid patients were reduced by levothyroxine replacement. Endocr J. 2007;54:45-52.

110. Chadarevian R, Jublanc C, Bruckert E, et al. Effect of levothyroxine replacement therapy on coagulation and fibrinolysis in severe hypothyroidism. J Endocrinol Investig. 2005;28:398-404.

111. Desideri G, Bocale R, D’Amore A, et al. Replacement therapy with levothyroxine modulates platelet activation in recent-onset post-thyroidectomy subclinical hypothyroidism. Nutr Metab Cardiovasc Dis. 2017;27:896-901.

112. Lippi G, Salvagno GL, Rugolotto S, et al. Routine coagulation tests in newborn and young infants. J Thromb Thrombolysis. 2007;24:153-5.

113. Li Y, Chen H, Tan J, Wang X, Liang H, Sun X. Impaired release of tissue plasminogen activator from the endothelium in Graves' disease-indicator of endothelial dysfunction and reduced fibrinolytic capacity. Eur J Clin Investig. 1998;28:1050-4. 
114. Liu L, Wang X, Lin Z, Wu H. Elevated plasma levels of VWF: Ag in hyperthyroidism are mediated through beta-adrenergic receptors. Endocr Res. 1993;19:123-33.

115. Myrup B, Bregengård C, Faber J. Primary haemostasis in thyroid disease. J Intern Med. 1995;238:59-63.

116. Sheu JJ, Kang JH, Lin HC, Lin HC. Hyperthyroidism and risk of ischemic stroke in young adults: a 5-year follow-up study. Stroke. 2010;41:961-6.

117. Elbers LP, Moran C, Gerdes VE, et al. The hypercoagulable state in hyperthyroidism is mediated via the thyroid hormone $\beta$ receptor pathway. Eur J Endocrinol. 2016; https://doi. org/10.1530/EJE-15-1249.

118. Akinci B, Demir T, Comlekci A, et al. Effect of levothyroxine suppression therapy on plasma thrombin activatable fibrinolysis inhibitor antigen levels in benign thyroid nodules. Med Princ Pract. 2011;20:23-8.

119. Demir T, Akinci B, Comlekci A, et al. Levothyroxine (LT4) suppression treatment for benign thyroid nodules alters coagulation. Clin Endocrinol (Oxf). 2009;71:446-50.

120. Hooper JM, Stuijver DJ, Orme SM, et al. Thyroid dysfunction and fibrin network structure: a mechanism for increased thrombotic risk in hyperthyroid individuals. J Clin Endocrinol Metab. 2012;97:1463-73.

121. Van Zaane B, Squizzato A, Debeij J, et al. Alterations in coagulation and fibrinolysis after levothyroxine exposure in healthy volunteers: a controlled randomized crossover study. J Thromb Haemost. 2011;9:1816-24.

122. Kreisman SH, Hennessey JV. Consistent reversible elevations of serum creatinine levels in severe hypothyroidism. Arch Intern Med. 1999;159:79-82.

123. Shin DH, Lee MJ, Kim SJ, et al. Preservation of renal function by thyroid hormone replacement therapy in chronic kidney disease patients with subclinical hypothyroidism. J Clin Endocrinol Metab. 2012;97:2732-40.

124. Sawka AM, Carty SE, Haugen BR, et al. American Thyroid Association guidelines and statements: past, present, and future. Thyroid. 2018;28:692-706.

125. Jonklaas J, Bianco AC, Bauer AJ, et al. Guidelines for the treatment of hypothyroidism: prepared by the American Thyroid Association Task Force on Thyroid Hormone Replacement. Thyroid. 2014;24:1670-751.

126. Thyroid disease: assessment and management. NICE guideline [NG145]. Nov 2019. Available at https://www.nice.org.uk/guidance/ng145/chapter/Recommendations. Accessed Jul 2020.

127. Stott DJ, Rodondi N, Kearney PM, et al. Thyroid hormone therapy for older adults with subclinical hypothyroidism. N Engl J Med. 2017;376:2534-44.

128. Surks MI, Hollowell JG. Age-specific distribution of serum thyrotropin and antithyroid antibodies in the US population: implications for the prevalence of subclinical hypothyroidism. J Clin Endocrinol Metab. 2007;92:4575-82.

129. Feller M, Snel M, Moutzouri E, et al. Association of thyroid hormone therapy with quality of life and thyroid-related symptoms in patients with subclinical hypothyroidism: a systematic review and meta-analysis. JAMA. 2018;320:1349-59.

130. Pearce SH, Brabant G, Duntas LH, et al. 2013 ETA guideline: management of subclinical hypothyroidism. Eur Thyroid J. 2013;2:215-28.

131. Bekkering GE, Agoritsas T, Lytvyn L, et al. Thyroid hormones treatment for subclinical hypothyroidism: a clinical practice guideline. BMJ. 2019;365:12006.

132. Biondi B, Cappola AR, Cooper DS. Subclinical hypothyroidism: a review. JAMA. 2019;322:153-60.

133. Somwaru LL, Rariy CM, Arnold AM, Cappola AR. The natural history of subclinical hypothyroidism in the elderly: the cardiovascular health study. J Clin Endocrinol Metab. 2012;97:1962-9.

134. Paragliola RM, Corsello A, Concolino P, et al. Iodothyronine deiodinases and reduced sensitivity to thyroid hormones. Front Biosci (Landmark Ed). 2020;25:201-28. 
135. Hennessey JV, Espaillat R. Current evidence for the treatment of hypothyroidism with levothyroxine/levotriiodothyronine combination therapy versus levothyroxine monotherapy. Int $\mathrm{J}$ Clin Pract. 2018;72:e13062.

136. Hennessey JV. Historical and current perspective in the use of thyroid extracts for the treatment of hypothyroidism. Endocr Pract. 2015;21:1161-70.

137. Wiersinga WM, Duntas L, Fadeyev V, Nygaard B, Vanderpump MP. 2012 ETA guidelines: the use of L-T4 + L-T3 in the treatment of hypothyroidism. Eur Thyroid J. 2012;1:55-71.

138. Jonklaas J, Tefera E, Shara N. Physician choice of hypothyroidism therapy: influence of patient characteristics. Thyroid. 2018;28:1416-24.

139. DiStefano J 3rd, Jonklaas J. Predicting optimal combination LT4 + LT3 therapy for hypothyroidism based on residual thyroid function. Front Endocrinol (Lausanne). 2019;10:746.

140. Okosieme O, Gilbert J, Abraham P, et al. Management of primary hypothyroidism: statement by the British Thyroid Association Executive Committee. Clin Endocrinol (Oxf). 2016;84:799-808.

141. Jørgensen P, Langhammer A, Krokstad S, Forsmo S. Diagnostic labelling influences self-rated health. A prospective cohort study: the HUNT Study, Norway. Fam Pract. 2015;32:492-9.

142. Bould H, Panicker V, Kessler D, et al. Investigation of thyroid dysfunction is more likely in patients with high psychological morbidity. Fam Pract. 2012;29:163-7.

143. Walsh JP, Ward LC, Burke V, et al. Small changes in thyroxine dosage do not produce measurable changes in hypothyroid symptoms, well-being, or quality of life: results of a doubleblind, randomized clinical trial. J Clin Endocrinol Metab. 2006;91:2624-30.

144. Samuels MH, Kolobova I, Niederhausen M, Janowsky JS, Schuff KG. Effects of altering levothyroxine (L-T4) doses on quality of life, mood, and cognition in L-T4 treated subjects. J Clin Endocrinol Metab. 2018;103:1997-2008.

Open Access This chapter is licensed under the terms of the Creative Commons Attribution 4.0 International License (http://creativecommons.org/licenses/by/4.0/), which permits use, sharing, adaptation, distribution and reproduction in any medium or format, as long as you give appropriate credit to the original author(s) and the source, provide a link to the Creative Commons license and indicate if changes were made.

The images or other third party material in this chapter are included in the chapter's Creative Commons license, unless indicated otherwise in a credit line to the material. If material is not included in the chapter's Creative Commons license and your intended use is not permitted by statutory regulation or exceeds the permitted use, you will need to obtain permission directly from the copyright holder. 